
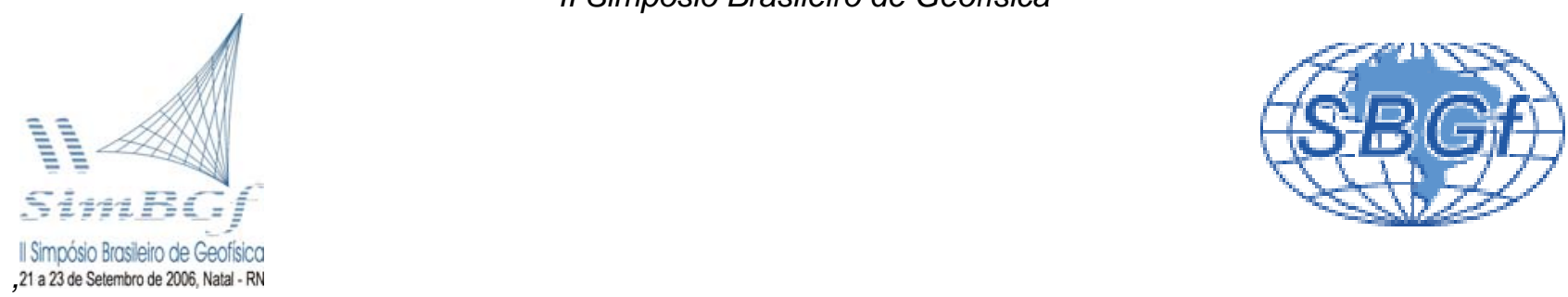

\title{
Estudo de Espessura Sedimentar na Bacia do Paraná com Funcão do Receptor de Alta Freqüência
}

Thiago Nobre Costa, Instituto de Astronomia, Geofísica e Ciências Atmosféricas - IAG/USP

Marcelo Assumpção, Instituto de Astronomia, Geofísica e Ciências Atmosféricas - IAG/USP

José Roberto Barbosa, Instituto de Astronomia, Geofísica e Ciências Atmosféricas - IAG/USP

Copyright 2006, SBGf - Sociedade Brasileira de Geofísica

Este texto foi preparado para a apresentação no II Simpósio de Geofísica da Sociedade Brasileira de Geofísica, Natal, 21-23 de setembro de 2006. Seu conteúdo foi revisado pela Comissão Tecno-científica do II SR-SBGf mas não necessariamente representa a opinião da SBGf ou de seus associados. E proibida a reprodução total ou parcial deste material para propósitos comerciais sem prévia autorização da SBG.

\section{Resumo}

Analisamos duas anomalias gravimétricas na Bacia do Paraná, próximo à divisa dos estados de Mato Grosso do Sul e Goiás. Essas anomalias podem estar relacionadas com o a topografia do embasamento. Para investigarmos essa possibilidade foram instaladas três estações sismológicas para complementar com os dados de outras duas estações já presentes na região. Foi utilizado a metodologia da função do receptor para obter a resposta da estrutura logo a abaixo da estação. Para obtermos os modelos de velocidade foram feitas inversões conjuntas das funções do receptor e com dados de curvas de dispersão de ondas de superfície. No final são apresentados os resultados preliminares que mostram boa correlação com alguns dados de poços e com as posições das anomalias.

\section{Introdução}

Investigamos duas anomalias gravimétricas na Bacia do Paraná (Moraes et al, 2006), próximo à divisa dos estados de Mato Grosso do Sul e Goiás. Usamos a Função do Receptor de alta freqüência para investigar as camadas sedimentares e verificar se existe alguma correlação dessas anomalias com a topografia do embasamento da bacia.

O método da Função do Receptor é usado com bastante sucesso no estudo da interface manto superior e crosta, sendo possível desenvolver mapas de espessura crustal de várias regiões do globo. Juntamente com a função do receptor, usamos neste trabalho dados de dispersões de ondas de superfície. Assim é possível realizar uma inversão conjunta dos dados das funções do receptor e das curvas de dispersão para se obter um modelo de velocidades da bacia e estimar a profundidade do embasamento. Essa abordagem foi realizada em recente trabalho sendo possível determinar a espessura da bacia sob estações e comparar os resultados obtidos com informações geológicas e dados de poços (An \& Assumpção, 2004b).

\section{Metodologia/ Problema Investigado}

O método da função do receptor considera que quando uma onda $P$ incide quase verticalmente sob uma interface, a forma de onda na componente vertical permanece praticamente inalterada, ou seja, a resposta das camadas acima dessa interface é considerada um delta. Na componente radial fica registrada a chegada da onda SV convertida na passagem da onda $P$ e suas reverberações. Temos então o registro da onda incidente na base da interface (componente vertical), e o registro da conversão P-SV e suas reverberações em superfície (componente radial) (Fig. 1).

Como mostrado inicialmente por Langdon (1979) a componente radial será a convolução de uma função resposta das camadas próximas a estação e a componente vertical. Essa função reposta no domínio do tempo é denominada função do receptor (FR).

Podemos deconvolver essa componente vertical da componente radial para obtermos a função do receptor. A abordagem proposta inicialmente foi a divisão espectral das componentes. Nesse trabalho usamos uma deconvolução no domínio do tempo (Ligorría e Ammon 1999). Os métodos de deconvolução, em geral, retornam o mesmo resultado, e as variações de resposta dependem da qualidade do dado. Para obtermos os modelos de velocidade invertendo somente as funções do receptor teríamos um problema de ambigüidade entre velocidade e profundidade das camadas (Ammon et al., 1990). Então para reduzirmos esse efeito usamos a inversão conjunta da função do receptor e das curvas de dispersão das ondas de superfície (Julià et al., 2000).

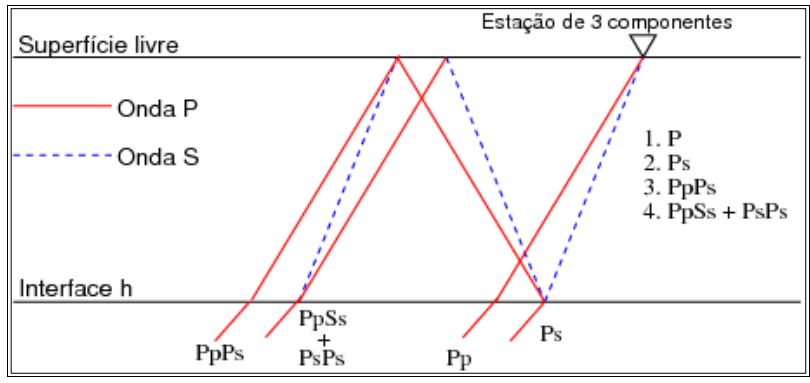

Figura 1 - Diagrama de raios para a incidência de uma onde $P$. A conversão Ps e as suas reverberções.

As curvas de dispersão para essa região foram obtidas de Feng et al. (2004) e Feng et al. (2006). 
Para calcular as funções do receptor usamos sismos com magnitude maior que 4.7, distância epicentral menor do que 25 graus, e profundidade maior que $100 \mathrm{~km}$. Todos esses requisitos visam assegurar um conteudo de freqüência maior. Como nosso alvo é a espessura da camada sedimentar acima do embasamento precisamos de comprimentos de ondas menores, ou seja, freqüências maiores. Como a terra é um filtro passabaixo optamos por eventos próximos. Para garantirmos a incidência vertical e evitarmos a atenuação da astenosfera próxima da fonte selecionamos também eventos mais profundos.

Antes da deconvolução, os sismogramas foram filtrados com passa-alta de $1 \mathrm{~Hz}$ para diminuir ruídos microssísmicos que causavam instabilidades na deconvolução. Para as deconvoluções usamos um filtro Gaussino de largura 10, ou seja, utilizamos freqüências até $5 \mathrm{~Hz}$ aproximadamente. Pra cada deconvolução o programa realizou 500 interações. Variamos as janelas de tempo de 10 a 20 segundos de 2 em 2 segundos e escolhemos as FR com melhor ajuste.

Para a inversão conjunta usamos um modelo com camadas de $100 \mathrm{~m}$ de espessura até $2 \mathrm{~km}$ e $200 \mathrm{~m}$ até 6 $\mathrm{km}$ e, a partir daí, $1 \mathrm{~km}$ de espessura. Agrupamos eventos próximos em clusters e invertemos as FR's por clusters.

\section{Resultados}

Foram calculadas as funções do receptor para as estações mostradas na Figura 2.

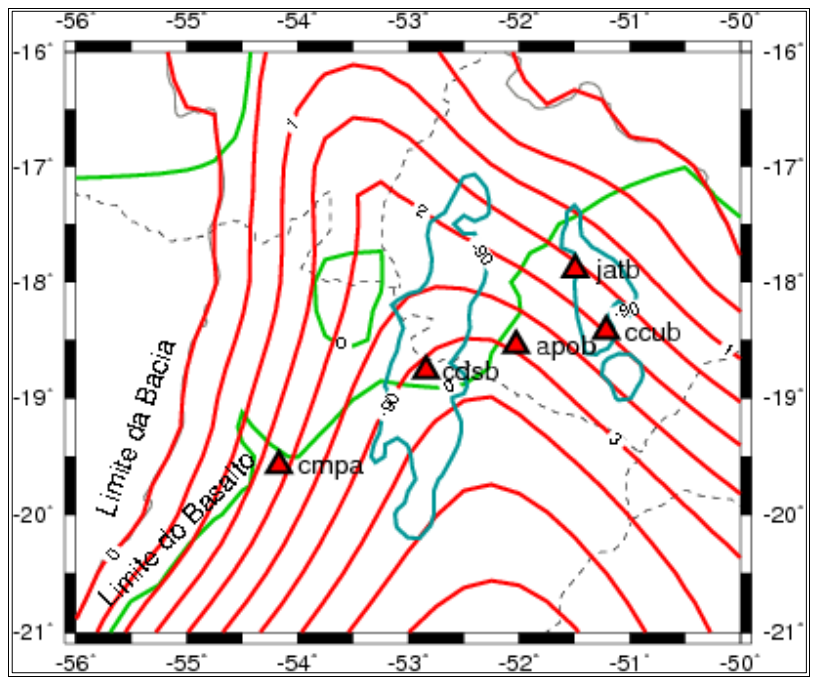

Figura 2 - Mapa das estações utilizadas. A linha azul mostra os baixos da anomalia Bouger. A linha vermelha é o contorno da profundidade do embasamento estimado por dados de poços. A linha verde é o limite do afloramento da camada de basalto Serra Geral.

Na Figura $3 a$ vemos as FR's para a estação CMPA. Vemos que o modelo ajusta bem os dados até aproximadamente $4 \mathrm{~s}$, o que significa que a precisão do modelo de velocidades diminui com a profundidade. Para as curvas de dispersão (Fig. 3b) podemos identificar para os períodos menores ( $<25 \mathrm{~s})$ um ajuste mais próximo do real pois também estão relacionadas às partes mais rasas do modelo. Como usamos um peso de 0.1 para as ondas de superfície e 0.9 para as FR's o ajuste das FR é mais significativo para os modelos.

O pico duplo da FR em torno de 0.3 s deve indicar uma fina camada superficial de baixa velocidade logo a baixo da estação. Isto é observado na Figura 3c até os 300m aproximadamente. Vemos também uma tendência de aumento de velocidade até os $2.2 \mathrm{~km}$ de profundidade onde ocorre um aumento rápido para $\mathrm{Vs}>3.5 \mathrm{~km} / \mathrm{s}$, interpretado como a interface do embasamento.

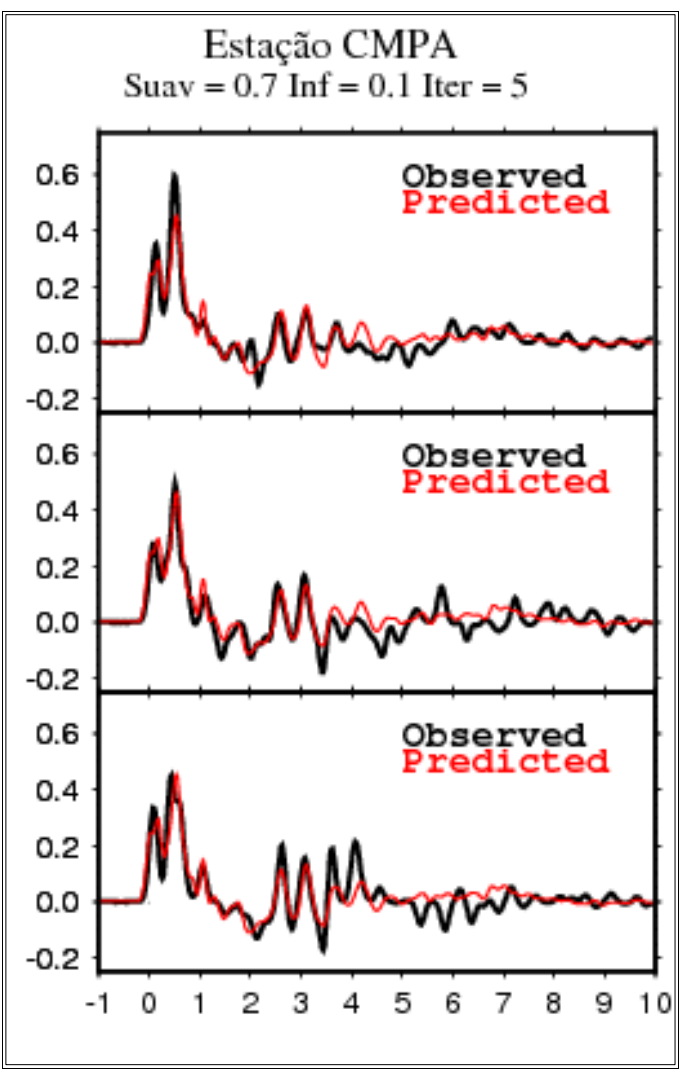

Figura 3a - FR invertidas. A linha vermelha é a FR ajustada e a preta a FR real.

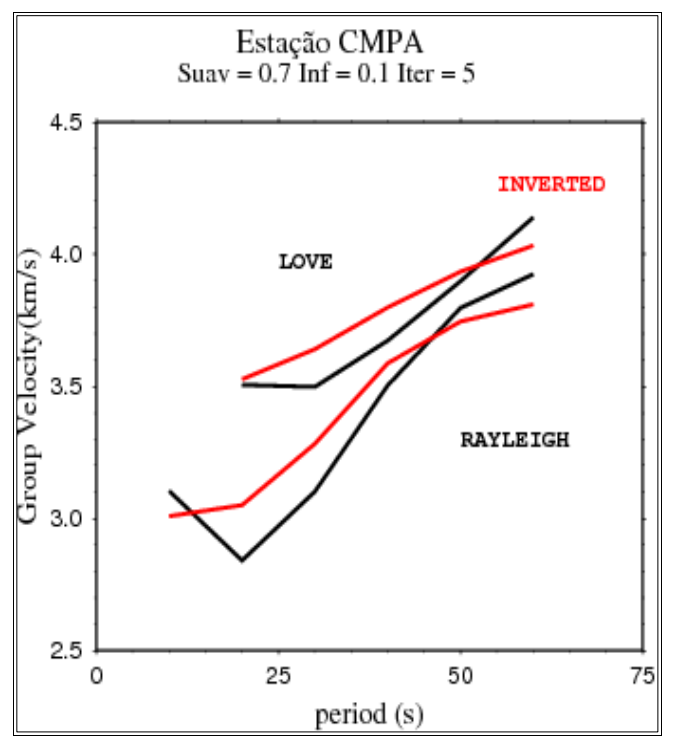

Figura $3 b-$ Ajuste das curvas de dispersão. A linha vermelha é a dispersão ajustada e a preta a real. 
$\mathrm{Na}$ Figura 4a mostramos as FR da estação CDSB. Esta estação esta dentro do baixo gravimétrico entre 52 e 53,5 graus W. A FR ajustada possui dois picos duplos em 0,1 e 0,5 quem não aparecem nas FR's reais. Essa feição aparentemente reflete-se no modelo (Fig. 4b) como o pequeno aumento de velocidade em $200 \mathrm{~m}$. O forte pico negativo em 1,2s marca uma inversão de velocidade que pode estar correlacionada com a inversão do modelo em torno de $1,8 \mathrm{~km}$.

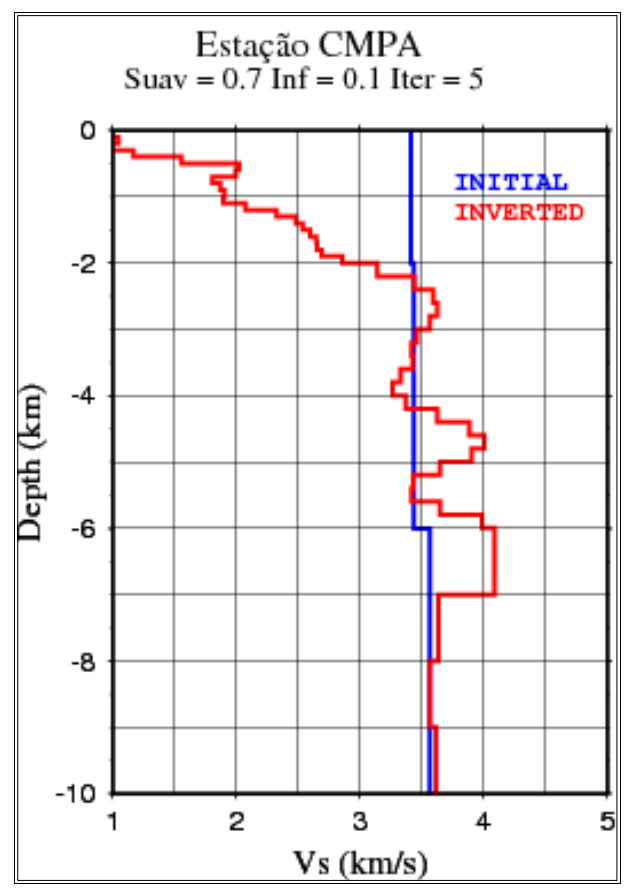

Figura 3c - Modelo obtido pela inversão conjunta. Podemos estimar a profundidade da bacia em torno de $2,2 \mathrm{~km}$

$\mathrm{Na}$ Figura $4 \mathrm{~b}$ vemos o modelo de velocidades obtido pela inversão conjunta das FR's e das curvas de dispersão. O modelo é mais complexo que o da estação CMPA, refletindo o padrão mais complexo das FR's da estação CDSB.

$\mathrm{Na}$ Figura 4b interpretamos a interface em $4,2 \mathrm{~km}$ como sendo o embasamento. A camada de alta velocidade entre 1 e $2 \mathrm{~km}$ pode ser correlacionada com a formação Serra Geral, mas ela estaria em uma profundidade bem maior que o esperado por dados de poços e afloramentos da formação.

Para a estação CCUB obtemos as FR's para um dos clusters e usamos o empilhamento dessas funções para calcular outra FR usando um filtro gaussinano menor para definir estruturas mais profundas. Assim na Figura 5 a vemos 4 FR's mas utilizamos somente 3 eventos para esse cluster. O sofware utilizado permite usar mais de uma largura de filtro Gaussiano.

A estação CCUB está instalada dentro do segundo baixo gravimétrico entre 50,5 e 52 graus W embora esteja próxima à borda. Ela também se encontra sobre um afloramento de basalto da formação Serra Geral. Vemos na Figura $5 \mathrm{a}$ que no tempo $0,1 \mathrm{~s}$ aproximadamente 0 modelo não ajusta bem o pico negativo, o que pode ser devido à suavização da inversão

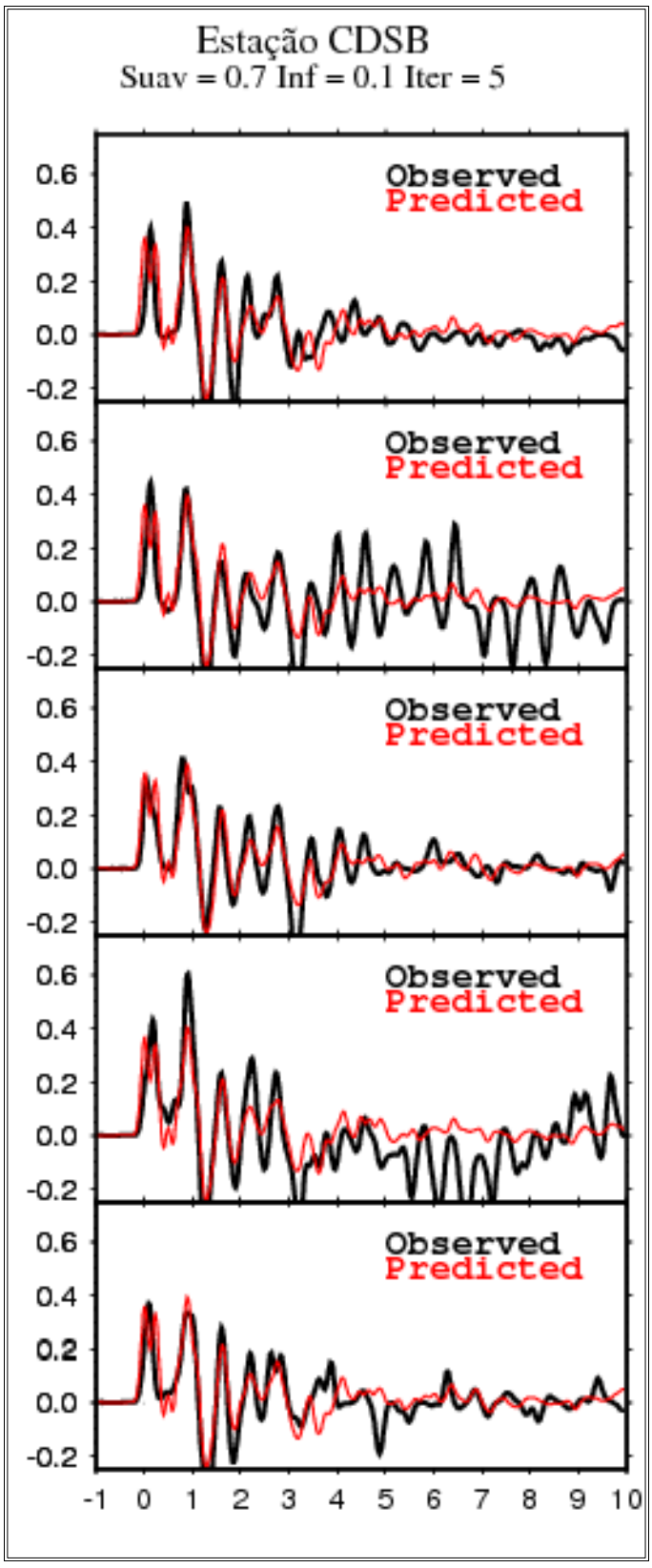

Figura $4 a-F R$ invertidas. A linha vermelha é a FR ajustada e a preta a FR real.

$\mathrm{Na}$ Figura $5 \mathrm{~b}$ vemos uma característica diferente das outras estações: uma velocidade superficial maior relacionada com o fato da estação estar montada sobre o basalto. Para o embasamento temos duas feições possíveis: em 2,2 km e $4 \mathrm{~km}$. Em 2,2 km teriamos um embasamento com profundidade esperada (contornos na Figura 2) se não houvesse o baixo gravimétrico. Neste caso, a causa da anomalia gravimétrica não estaria na profundidade do embasamento. No caso de um embasamento a $4 \mathrm{~km}$, teríamos justamente o caso oposto: a anomalia poderia ser causada por esse baixo na topografia do embasamento.

Na estação APOB temos uma situação parecida: um bom ajuste das FR's e um modelo de velocidades com duas interpretações possíveis (Figura 6a e 6b). 


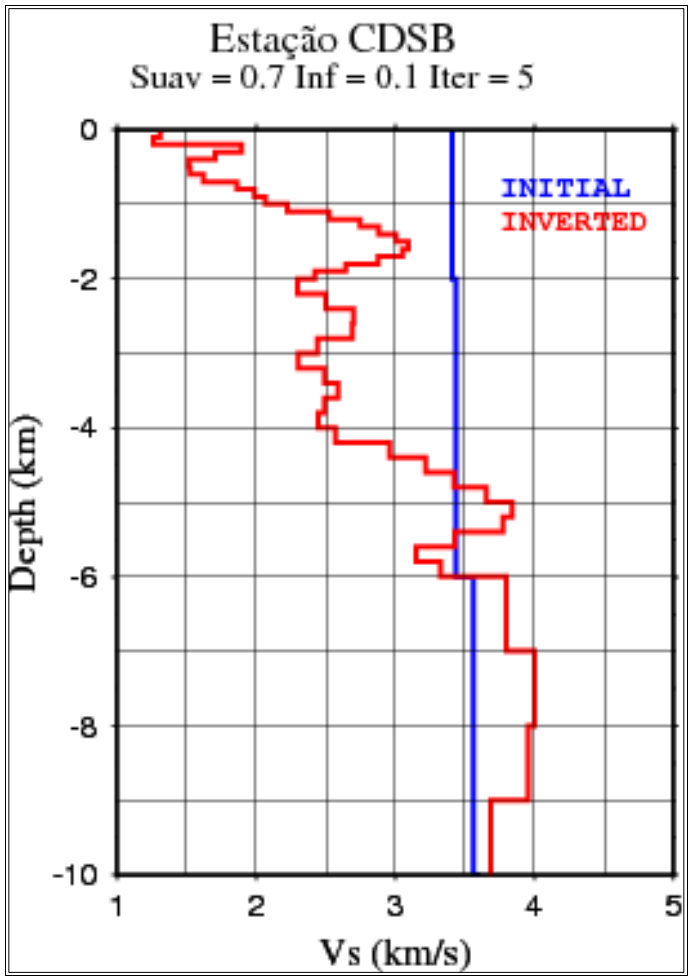

Figura $4 b$ - Modelo obtido pela inversão conjunta. Podemos estimar a profundidade da bacia em torno de $4,2 \mathrm{~km}$

Percebemos duas feições possíveis para o embasamento, em $2 \mathrm{~km}$ e em 3,6km (Figura 6b). Próximo a essa estação( $\approx 50 \mathrm{~km})$ temos um dado de poço com profundidade do embasamento de $3,47 \mathrm{~km}$. Para o nosso modelo podemos interpretar a feição de $3,6 \mathrm{~km}$ como a profundidade do embasamento.

Para a estação JATB fizemos um empilhamento das FR's de um mesmo cluster e invertemos essa FR empilhada (Fig. 7a). A inversão das FR's separadamente da resultado muito similar. Para esta estação interpretamos um embasamento em torno de $3,4 \mathrm{~km}$.

\section{Discussão e Conclusões}

Estes resultados preliminares são bastante coerentes mostrando que a função do receptor com alta frequência pode trazer bons resultados. Ainda é necessário correlacionar estas profundidades do embasamento com os dados de gravimetria após remoção do campo regional.

Os dados serão trabalhados a fim de remover ambiguidades nas interpretações, se possível, como no caso da estação CCUB. Outros softwares foram utilizados obtendo-se modelos parecidos, mas com diferenças perceptiveis. Tais casos devem ser estudados para uma abordagem mais completa do método.

As interpretações da profundidade do embasamento são mostradas na Figura 8.

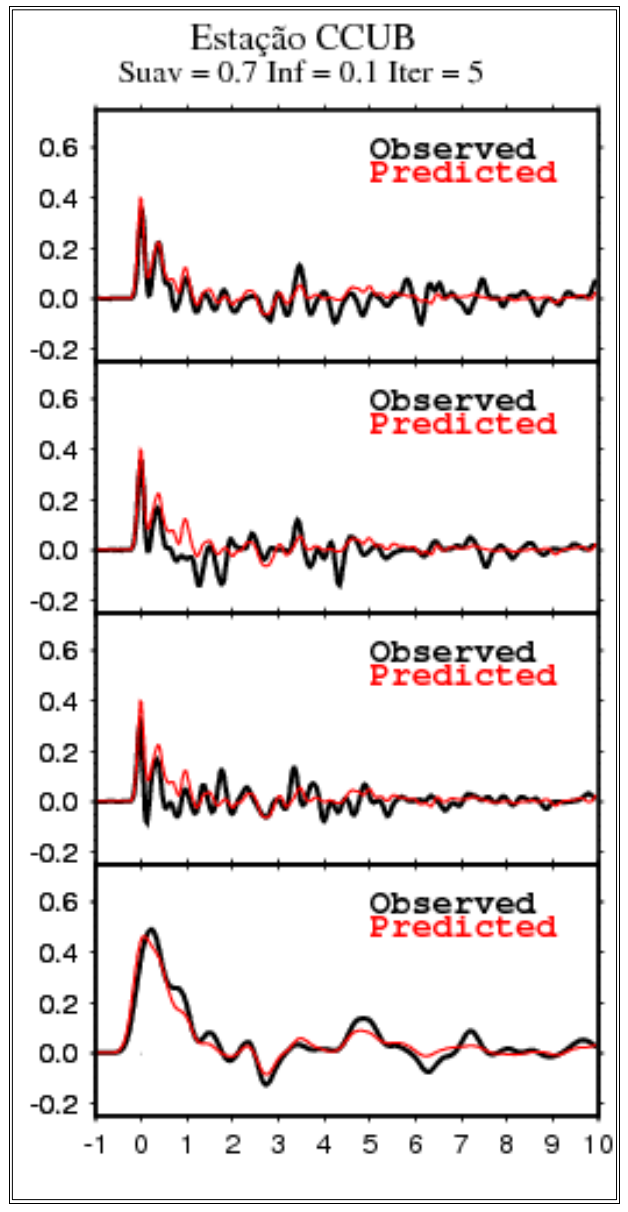

Figura $5 a-F R$ invertidas. A linha vermelha é a FR ajustada e a preta a FR real.

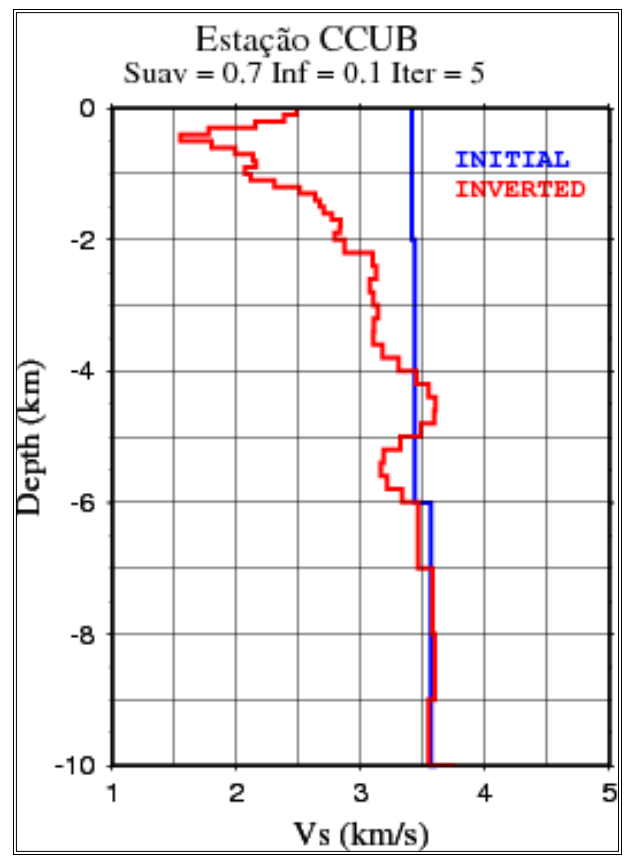

Figura $5 b$ - Modelo obtido pela inversão conjunta. Podemos interpretar a profundidade do embasamento tanto em 2,2 km ou $4 \mathrm{~km}$ 


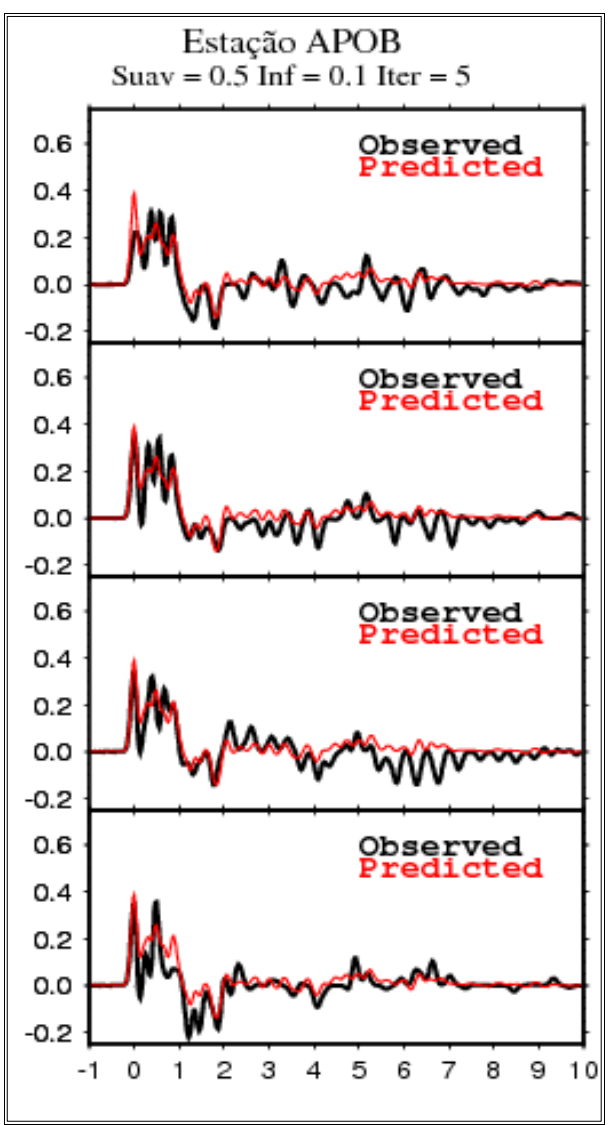

Figura 6a - FR invertidas. A linha vermelha é a FR ajustada e a preta a FR real.

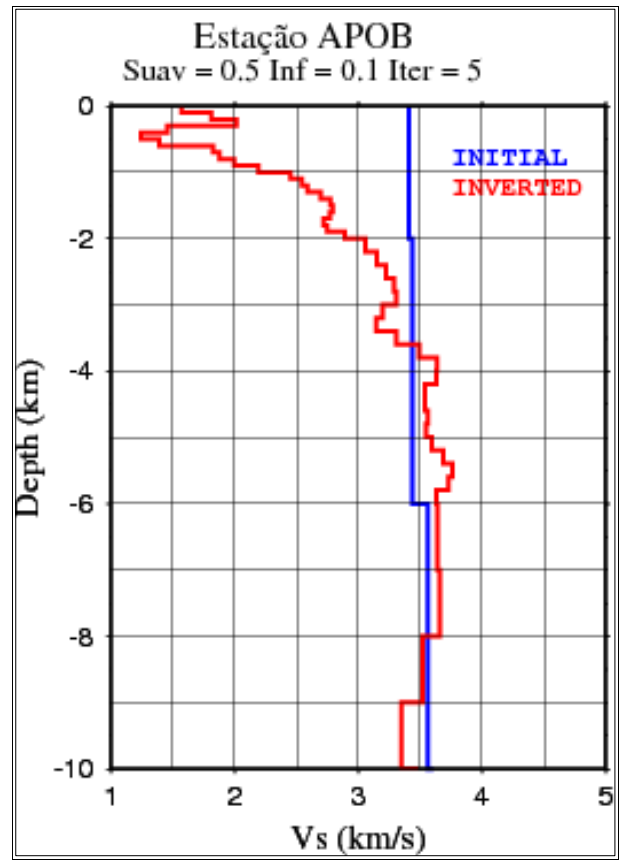

Figura $6 b$ - Modelo obtido pela inversão conjunta. Podemos interpretar a profundidade do embasamento pelo modelo e por dado de poço em $3,6 \mathrm{~km}$

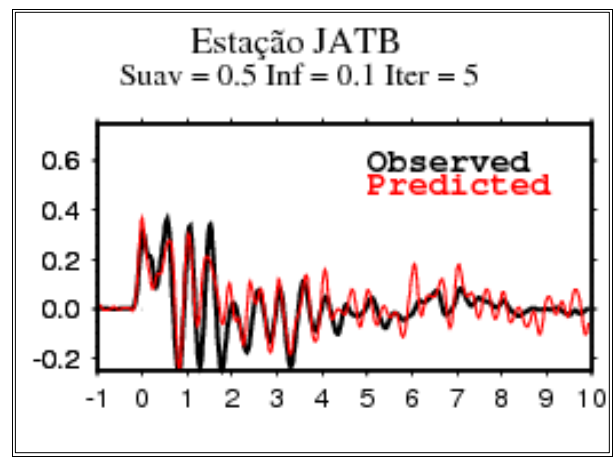

Figura $7 a-F R$ em pilhada e invertida. A linha vermelha é a FR invertida e a preta a FR empilhada.

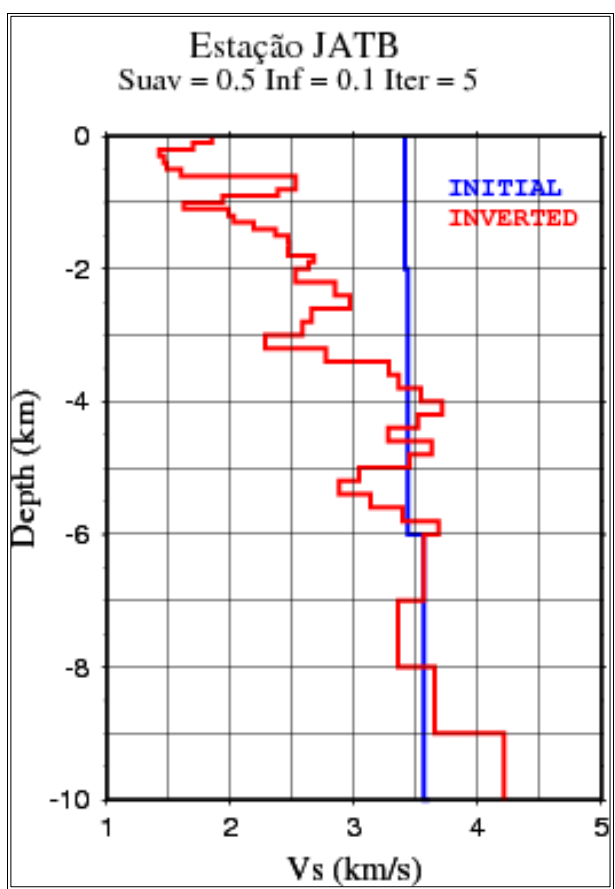

Figura $7 b$ - Modelo obtido pela inversão conjunta. Podemos interpretar a profundidade do embasamento pelo modelo e por dado de poço em $3,6 \mathrm{~km}$

\section{Agradecimentos}

Agradecemos a Fapesp que finaciou o trabalho. Ao amigo Marcelo Bianchi pela ajuda, discussão e paciência no dia a dia do trabalho.

\section{Referências}

An, M. \& Assumpção, M., 2004b. Basement depth in the Paraná Basin with high frequency receiver functions. I Simpósio de Geofísica da SBGf, São Paulo, 2628/09/2004. 
Langston, C.A., 1979. Structure under Mount Rainier, Washington, inferred from teleseismic body waves: J. Geophys. Res., 85, 4749-4762.

Feng, M. \& M. Assumpção, 2004. Group-velocity tomography and lithospheric S-velocity structure of the South American continent, Phys. Earth Planet. Int. 147, 315-331.

Feng, M., S. van der Lee \& M. Assumpção, 2006. Upper mantle structure of South America from joint inversion of waveforms and fundamental-mode group velocities of Rayleigh waves. J. Geophys. Res., submitted.

Ligorría, J.P. \& C. Ammon, 1999. Iterative deconvolution and receiver-function estimation. Bull. Seism. Soc. Am., 89, 1395-1400.
Ammon, C., Randall, G. \& Zandt, G, 1990. On the nonuniqueness of receiver function inversions. $J$. Geophys. Res., 95, 15303-15318.

Julià J., Ammon, C.J., Herrmann, R.B. \& Correig, A. M., 2000. Joint inversion of receiver function and surface wave dispersion observations. Geophys. J. Int.,143, 99112.

Moraes R.F., Junior V.C.O.\& Maragoni Y.R., 2006 Estudo de anomalias gravimétricas na borda norte da bacia do Paraná. Simpósio de Geofísica da SBGF, Natal, 2123/09/2006.

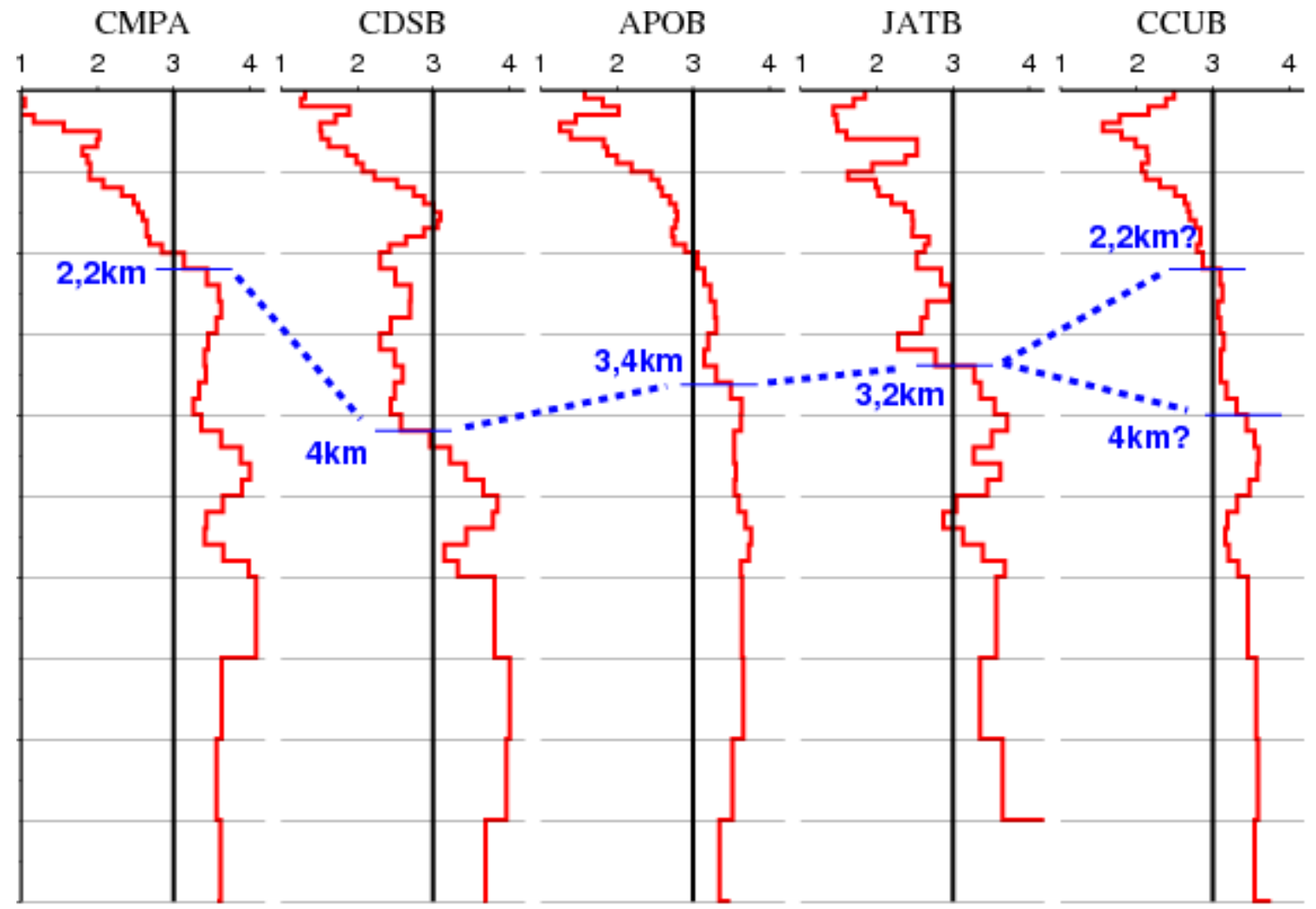

Figura 8 - Seção de modelos estruturais. As linhas cinzas horizontais são profundidades em intervalos de $1 \mathrm{~km}$. Os números na parte superior são velocidades da onda $S(\mathrm{~km} / \mathrm{s})$. A linha vertical de referência corresponde a Vs=3,0 km/s e $V p=5,2 \mathrm{~m} / \mathrm{s}$ Velocidades $S$ maiores que $3,5 \mathrm{~km} / \mathrm{s}$ são típicas de embasamento cristalino. 